\title{
Electrical and ion beam analyses of Yttrium and Yttrium-Titanium getter thin films oxidation
}

\author{
Clément Bessouet ${ }^{1}$, Sylvain Lemettre ${ }^{1, a)}$, Charlotte Kutyla ${ }^{1}$, Alain Bosseboeuf \\ ${ }^{1}$, Philippe Coste ${ }^{1}$, Thierry Sauvage ${ }^{2}$, Hélène Lecoq ${ }^{2}$, Olivier Wendling ${ }^{2}$, \\ Aurélien Bellamy ${ }^{2}$, Piyush Jagtap ${ }^{3}$, Stéphanie Escoubas ${ }^{3}$, Christophe Guichet \\ ${ }^{3}$, Olivier Thomas ${ }^{3}$, Johan Moulin ${ }^{1}$ \\ ${ }^{1}$ C2N, Centre de Nanosciences et de Nanotechnologies, Université Paris-Saclay, \\ CNRS, UMR 9001, 91120 Palaiseau, France. \\ ${ }^{2}$ CEMHTI, Conditions Extrêmes et Matériaux : Haute Température et Irradiation, \\ CNRS, UPR 3079, 45071 Orléans Cedex 2, France. \\ 3 IM2NP, Institut Matériaux Microélectronique Nanosciences de Provence, \\ CNRS, UMR 7334, 13397 Marseille Cedex 20, France.

\section{a) sylvain.lemettre@universite-paris-saclay.fr}

Abstract. Yttrium, Titanium and Yttrium-Titanium getter thin films were elaborated on silicon by co-evaporation in ultra-high vacuum. Y-Ti films exhibit nanometric crystallites size $(18-35 \mathrm{~nm})$ leading to a very high grain boundary density, which is a favorable microstructure for an activation at low temperature. The yttrium content in Y-Ti alloys influences grain size, resistance against room temperature oxidation and gettering performance for oxygen. Y-Ti films with an yttrium content higher than $30 \%$ show strong oxygen sorption during annealing at low temperature (< $300{ }^{\circ} \mathrm{C}$ ). After $1 \mathrm{~h}$ of annealing at $250^{\circ} \mathrm{C}$, it was estimated that the yttrium-based getter films can trap between 0.2 and $0.5 \mu \mathrm{mol}$ of oxygen per $\mathrm{cm}^{2}$, while no oxygen sorption was detected for a single metal titanium film. This make Y-Ti getter alloys attractive candidates for the packaging of MEMS under vacuum with a low bonding temperature.

Keywords: Yttrium alloys, oxidation, getter, thin films, low-temperature bonding, MEMS packaging. 


\section{INTRODUCTION}

Vacuum is mandatory for the optimal operation of many kinds of microelectromechanical systems (MEMS) such as resonant sensors, bolometers or RF switches. In industry, vacuum packaging is more and more realized by wafer-level packaging (WLP) processes. To maintain the required vacuum level during the 10 to 20 years of the MEMS lifetime, hermetic sealing is combined with the integration of a getter film. A key parameter is the bonding temperature, because it drives outgassing inside the cavity and the activation of the getter film ${ }^{1}$.

Getter films presenting a low activation temperature are object of numerous studies since about 1998 , especially by the CERN ${ }^{2}$. The lowest activation temperatures reported are $133{ }^{\circ} \mathrm{C}$ and $150{ }^{\circ} \mathrm{C}$ for $\mathrm{Pd} / \mathrm{Ti}^{3}$ and $\mathrm{Ti}-\mathrm{Zr}-\mathrm{Hf}-\mathrm{V}^{4}$ films respectively. However the use of these getters for MEMS packaging was never reported and is then restricted to ultra-high vacuum (UHV) systems like particle accelerators. This must come from the great difference in specifications between UHV systems and MEMS packaging due to a different gaseous environment during activation ${ }^{5}$.

Getter films used in MEMS packaging are typically multilayers or alloys of highly reactive transition metals $(\mathrm{Ti}, \mathrm{Zr}, \mathrm{V}, \mathrm{Co} . .$.$) , eventually doped with rare earths, and$ eventually covered with a thin passivating overlayer and/or deposited on a sublayer ${ }^{5}$. Since 2010, highly hermetic sealing of MEMS-sized cavity at wafer-scale was demonstrated with low bonding temperatures $\left(200-300^{\circ} \mathrm{C}\right)$ and duration times $(\leq 1$ hour$)$, for example by transient liquid phase bonding with $\mathrm{Au}-\mathrm{In}^{6}$ or $\mathrm{Cu}-\mathrm{Sn}^{7}$ or by thermocompression bonding with $\mathrm{Cu}-\mathrm{Cu}^{8,9}$ or $\mathrm{Au}-\mathrm{Al}^{10}$. However, there is still no direct 
proof of a getter thin film compatible with these low temperatures bonding processes in the literature. The lowest bonding temperature reported for a functional WLP process with a getter film is $300{ }^{\circ} \mathrm{C}$ with a 30 min bonding time ${ }^{11}$, but the getter material was not specified.

In this paper, we present preliminary results concerning a new generation of getter films containing yttrium. Contrary to its close neighbors in the periodic table $\mathrm{Ti}, \mathrm{Zr}$, or V, yttrium has received little attention as a getter material, despite it is an excellent nonreversible getter for hydrogen ${ }^{12}$ and a material with a high oxygen diffusivity ${ }^{5}$. Furthermore, it has been shown that it can reduce, as a doping element, the activation temperature of a $\mathrm{Zr}$-Co sintered getter ${ }^{13}$.

In this work we investigated single metal yttrium and binary alloy Y-Ti thin films activation under a gaseous environment with high partial pressures of $\mathrm{O}_{2}$ and $\mathrm{H}_{2} \mathrm{O}$. Titanium was chosen to be combined with yttrium because of its excellent gettering properties $^{14}$ and because it is complementary to yttrium in terms of oxygen diffusivity and solubility: titanium has a low oxygen diffusivity and a high oxygen solubility, while yttrium has a high oxygen diffusivity and a low solubility ${ }^{5}$ Y-Ti thin films have been also scarcely studied ${ }^{15}$.

\section{EXPERIMENTAL}

200 nm-thick yttrium, titanium and Y-Ti films were deposited by using UHV ee-beam co-evaporation at room temperature on $100 \mathrm{~mm}$ silicon wafers. Titanium and Yttrium grains with a purity of $99.99 \%$ and $99.9 \%$ respectively were evaporated from alumina coated conical crucibles.. The background pressure before deposition was lower 
than $1.0 \times 10^{-8}$ mbar. The pressure during evaporation did not exceed $4.0 \times 10^{-8}$ mbar and was almost exclusively composed of $\mathrm{H}_{2}$ gas, as measured by residual gas analysis. Y-Ti alloys were obtained by varying the deposition rate ratio of yttrium to titanium, with a maximum total deposition rate in the $0.5-1 \mathrm{~nm} / \mathrm{s}$. The unloading of the wafer after deposition was realized by introducing nitrogen in the loadlock chamber. A 200 nm-thick yttrium film capped in situ with a 10 nm-thick gold layer was also deposited on silicon with the same evaporation set-upThe wafer was kept under UHV between the deposition of the Y and Au layers.

To simulate the activation process with a high partial pressure of oxidizing gases, yttrium and Y-Ti samples were annealed in a furnace under $99.9999 \%$ pure Ar with traces of oxidizing gases, at $1 \mathrm{~atm}$, for $1 \mathrm{~h}$, and at temperatures ranging from $225^{\circ} \mathrm{C}$ to $400{ }^{\circ} \mathrm{C}$. The argon flow during annealing was adjusted to $2000 \mathrm{sccm}$. For each annealing temperature, all samples of different compositions were annealed at the same time. The effective gas purity at the sample level could not be assessed but it contains at least a few ppm traces of oxidizing species corresponding to a partial pressure larger than $10^{-3} \mathrm{mbar}$.

Sheet resistance of the films was measured by the 4 point probe method at room temperature. The Temperature Coefficient of Resistance (TCR) was determined by using the method described by S. Lemettre et al. ${ }^{16}$.

Surface microstructure of as-deposited and annealed films was observed by SEM. The mean grain size of the film was estimated by using the mean linear intercept method in accordance with ASTM E112 standard. The microstructure and phase identification were carried out using an X-ray diffractometer (Philips-Panalytical) with $\mathrm{Cu} \mathrm{K} \alpha$ source. The samples were analyzed in standard Bragg-Brentano geometry by varying the angle 
$2 \theta$ from $25^{\circ}$ to $45^{\circ}$. The diffracted peaks were identified using reference data from powder samples.

Ion Beam Analyses (IBA) techniques were used to determine the atomic composition of the films. First, Rutherford Backscattering Spectroscopy (RBS) analyses were performed with a beam of ${ }^{4} \mathrm{He}$ at $2 \mathrm{MeV}$ to control the metallic elements composition and their in-depth homogeneity in the films. The detector is a $25 \mathrm{~mm}^{2}$ PIPS located at a $166^{\circ}$ angle with the beam. A better quantification of the light elements such as oxygen was obtained using Nuclear Reaction Analysis (NRA) performed with a deuteron beam at $900 \mathrm{keV}$. The oxygen content is measured by the ${ }^{16} \mathrm{O}\left(\mathrm{d}, \alpha_{0}\right){ }^{14} \mathrm{~N}$ nuclear reaction at $166^{\circ}$. Combination of these techniques and their analysis by SIMNRA software $^{17}$ with SigmaCalc cross section ${ }^{18}$ allows determining the in-depth concentration profiles of oxygen and metals in the films.

Finally, sorption of activated pure yttrium and Y-Ti films was characterized inside sealed glass ampoules. Twenty silicon square samples with a getter film deposited on them corresponding to a total getter surface area of $102 \mathrm{~mm}^{2}$ were inserted inside a glass ampoule. Four ampoules were prepared, each one filled with a getter film having a different composition. The getter films inserted in the ampoules had been previously exposed during 10 months to air at room temperature. A fifth ampoule without any sample was also prepared as a reference. Then the glass ampoules were connected to a pumping station. Once a $10^{-6}$ mbar internal pressure was reached, the ampoules were sealed off by a localized heating of the ampoule end. The five ampoules were then annealed during 1 $\mathrm{h}$ at $250{ }^{\circ} \mathrm{C}$. Once cooled down to ambient temperature, the residual gas composition inside the ampoules was measured by Oneida Research Services by the Internal Vapor Analysis (IVA) method based gas analysis by mass spectrometry 


\section{RESULTS AND DISCUSSION}

\section{A. Single metal yttrium}

Exposure of a getter to air is unavoidable in a MEMS packaging process flow. Curzon $^{19}$ stated that evaporated yttrium exposed to ambient air passivates, but the measurement was limited to few minutes. In the same way, Burnham ${ }^{20}$ measured only 5 nm of yttrium oxide after 2 months. Conversely, Reichl ${ }^{21}$ measurthed a growth of an $\mathrm{Y}_{2} \mathrm{O}_{3}$ oxide layer during one year. Finally, Huiberts ${ }^{12}$ demonstrated that oxygen diffuses deeply in an yttrium covered with an insufficiently thick Pd layer: oxygen was measured down to $175 \mathrm{~nm}$ in the bulk of the film, but after an unknown period of time. These contradictory observations indicate that oxidation of evaporated yttrium films is highly sensitive to the

deposition conditions. Recent observations by Moldarev ${ }^{22}$ on sputtered Y-O-H films concluded that the native oxide layer is not self-passivating for oxygen.

A continuous measurement of the sheet resistance was performed on 190-250 nm yttrium films after deposition by e-beam-evaporation under UHV for the following three different conditions: i) in ambient air; ii) exposed to ambient air for less than 10 min, then kept under vacuum $\left(<10^{-7} \mathrm{mbar}\right)$ for 46 days, and then exposed again to air; and iii) in ambient air after in situ deposition of an additional $10 \mathrm{~nm}$-thick gold capping layer (see Figure 1).

When exposed to air, the sheet resistance of an yttrium film rapidly increased during the first three days, then slowly afterwards. After 800 days of storage in ambient air, it increased by $70 \%$. For the film stored under vacuum, the sheet resistance increased only by a few percent during measurement over 46 days. Upon air exposure afterwhile, 
its sheet resistance rapidly increases and extrapolation at very long storage durations shows that the steady-state final value is the same as for the sample measured in ambient air. Thus the sheet resistance increase is clearly related to air exposure. By considering a parallel-resistance model for multilayer films ${ }^{23}$, we can attribute the increase of resistance to the continuous oxidation of the conductive metallic layer leading to an insulating oxide layer. This is in coherence with the oxide growth during ambient air exposure measured by Reichl $^{21}$ (see Figure 1).

The dependence of sheet resistance with air oxidation was also confirmed by the sheet resistance measurement of the yttrium film passivated with Au cap layer: the sheet resistance was stable over 60 days because conversely to yttrium native oxide, gold prevents yttrium air oxidation. Only a small increase is observed the first 4 days, for a reason to that could not be determined.

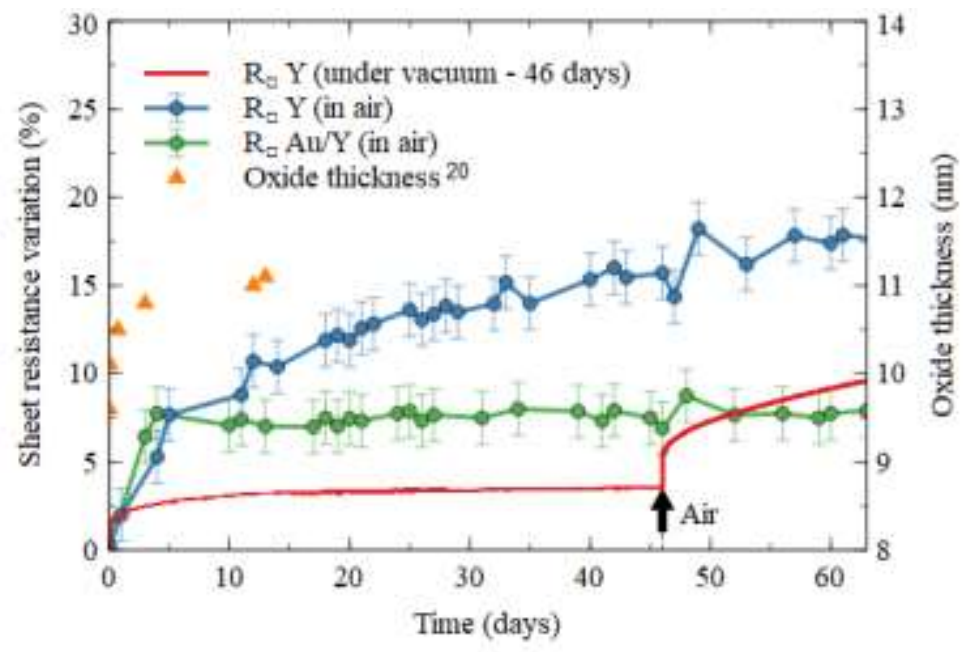

FIG. 1. Sheet resistance monitoring over time of three yttrium films stored at ambient air or under vacuum (start of the measurement: $<10 \mathrm{~min}$ after exposure to air). 
Figure 2 displays the oxygen profile in yttrium measured by NRA after 14 and 370 days of storage in ambient air. In both cases, the oxygen content at the surface is $60 \%$, what corresponds to $\mathrm{Y}_{2} \mathrm{O}_{3}$ composition. The thickness of this $\mathrm{Y}_{2} \mathrm{O}_{3}$ layer is $85 \times 10^{15}$ at $/ \mathrm{cm}^{2}$ which corresponds to a thickness of $12 \pm-2.5 \mathrm{~nm}$ if we consider a density of bulk $\mathrm{Y}_{2} \mathrm{O}_{3}$ equal to $5.01 \mathrm{~g} / \mathrm{cm}^{3}$ and apacking density of 0.91 (value measured for evaporated $\left.\mathrm{Y}_{2} \mathrm{O}_{3}{ }^{24}\right)$. THis thickness value is close to the value of $11 \mathrm{~nm}$ measured by Reich ${ }^{21}$ after 13 days of storage in air.

Oxygen atoms are detected not only at the surface but also in depth, with a concentration decreasing with depth. Because of the very low partial pressures of $\mathrm{H}_{2} \mathrm{O}$ and $\mathrm{CO}_{\mathrm{x}}$ oxidizing species during deposition (lower than $10^{-8} \mathrm{mbar}$ ), these oxygen atoms are essentially arising from air exposure rather than from contamination during evaporation. The oxygen profile after 370 days of air exposure shows that in depth oxidation was not avoided by the presence of $\mathrm{Y}_{2} \mathrm{O}_{3}$ at the surface. The Oxygen/Yttrium atomic ratio integrated in the film depth increased from 0.27 to 0.37 , meanwhile the sheet resistance increased by $10 \%$.

Hence, our results are in opposition with a surface passivation after few minutes as observed by Curzon ${ }^{19}$ or with a very limited growth found by Burnham ${ }^{20}$. However they are in agreement with the in-depth oxidation through grain boundaries observed by Huiberts $^{12}$ and with the results of Moldarev ${ }^{22}$ on Y-O-H films. 


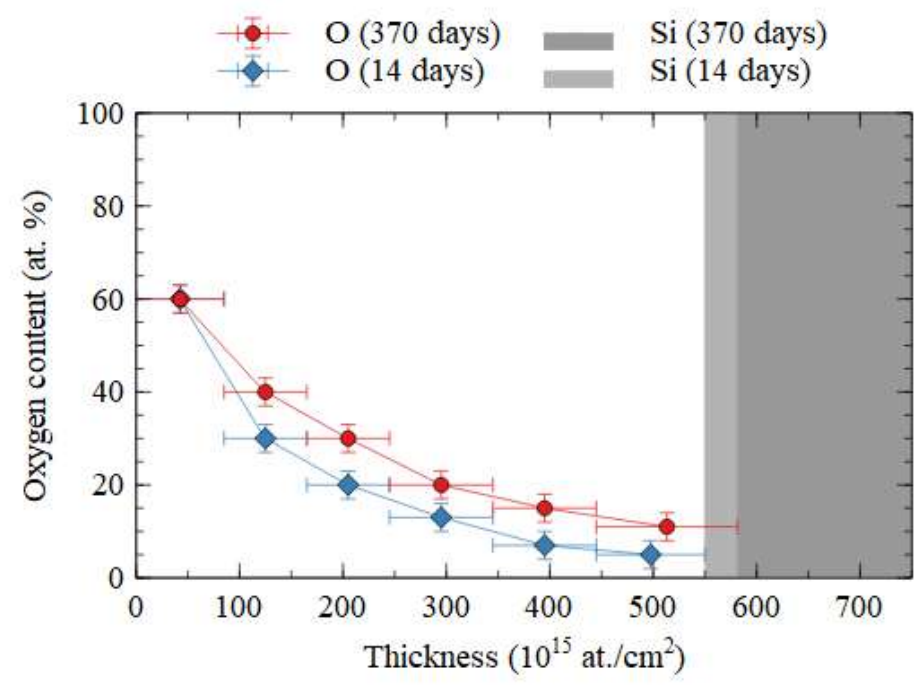

FIG. 2. Oxygen profile in a $200 \mathrm{~nm}$-thick yttrium film after two different times of exposure to air.

An XRD analysis of the yttrium film after air exposure during 6 months is shown in Figure 3. It confirms the presence of yttrium with an hexagonal close packed structure $(\mathrm{a}=\mathrm{b}=3.65 \AA$ and $\mathrm{c}=5.73 \AA$ ). The higher intensity of the Y 002 peak as compared with the 101 peak (the shoulder on the high-angle side of the 002 peak) indicates a strong texture in the films. Pole figures performed on Y 002 and Y 101 confirmed a $<001>$ fiber texture. The yttrium oxide $\mathrm{Y}_{2} \mathrm{O}_{3}$ peak was not detected in as-deposited samples even after 6 months of aging in ambient conditions. This is probably because XRD is much less sensitive to minority phases than the other techniques used in this study. In addition an amorphous or nanocrystallized yttrium oxide is particularly difficult to detect because $222 \mathrm{Y}_{2} \mathrm{O}_{3}$ peak and $002 \mathrm{Y}$ peaks are very close with $2 \theta$ at $29.26^{\circ}$ and $31.19^{\circ}$, respectively. The oxide peak is also absent in the $\mathrm{Au} / \mathrm{Y}$ analysis, showing an oxidation below the detection limit of the capped yttrium film, in agreement with the sheet resistance measurements. However, an oxide peak appeared and became more intense after a long period of ambient storage (> 1 year) and upon annealing of the films at higher 
temperatures. The oxide phase was identified as cubic $\mathrm{Y}_{2} \mathrm{O}_{3}(\mathrm{a}=\mathrm{b}=\mathrm{c}=10.39 \AA)$. The shift in the peak positions of (111) $\mathrm{Y}_{2} \mathrm{O}_{3}$ and (002) $\mathrm{Y}$ after annealing is also evident from XRD measurements, which may be due to stress induced by oxidation. This will be investigated in more details in a future work.

A Scherrer analysis of the peak widths yields crystallite sizes of $35 \mathrm{~nm}$ for yttrium, and $50 \mathrm{~nm}$ for the yttrium oxide layer in the out-of-plane direction. Figure 4 displays an image of the sample surface observed by SEM. It also clearly evidences the presence of grains at the film surface. The observed in-plane mean size of the grains is $22 \mathrm{~nm}$. The high density of grain boundaries deduced from XRD and SEM analyses, together with oxygen depth profiling by NRA, explain the very high value of yttrium film resistivity (>170 $\mu \Omega . \mathrm{cm})$, even after only 10 minutes air exposure, compared to the bulk value (58.5 $\mu \Omega . \mathrm{cm})$.

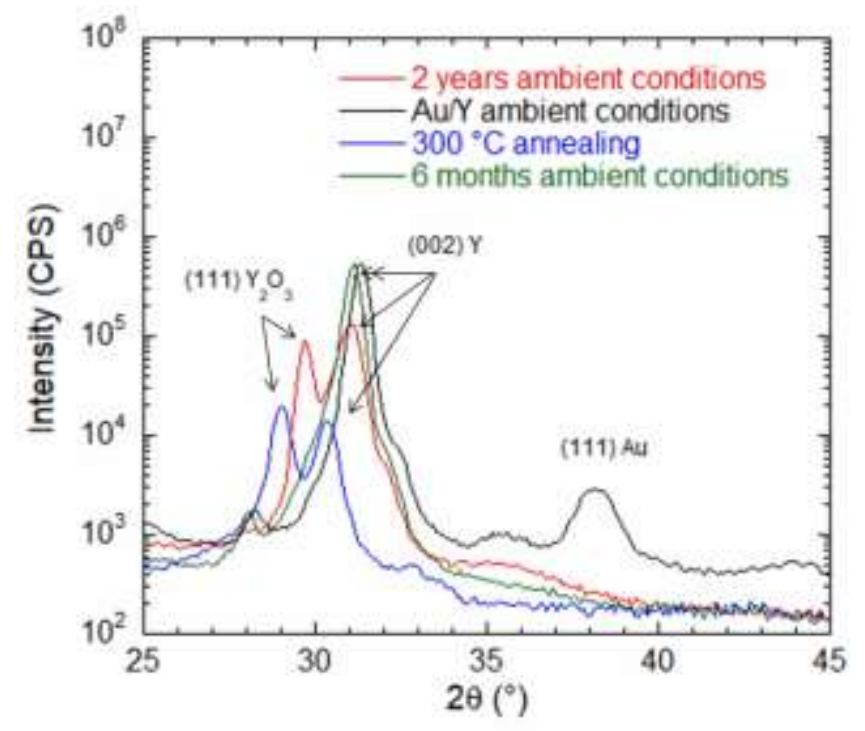

FIG. 3. XRD analysis of evaporated yttrium films after different exposures to oxygen. 


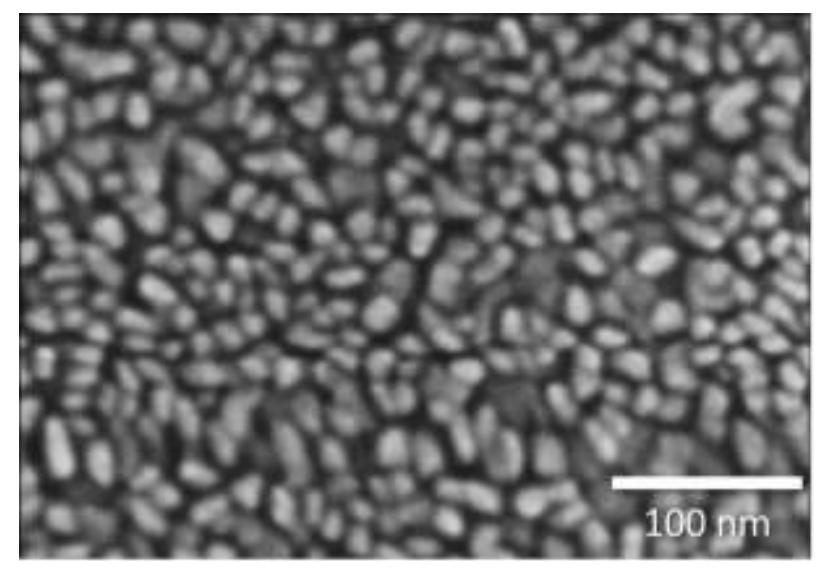

FIG. 4. SEM observation of the surface of an yttrium film.

Figure 5 shows the results of electrical measurements and RBS-NRA analyses performed at room temperature on samples annealed in a furnace under 1 atm of argon.

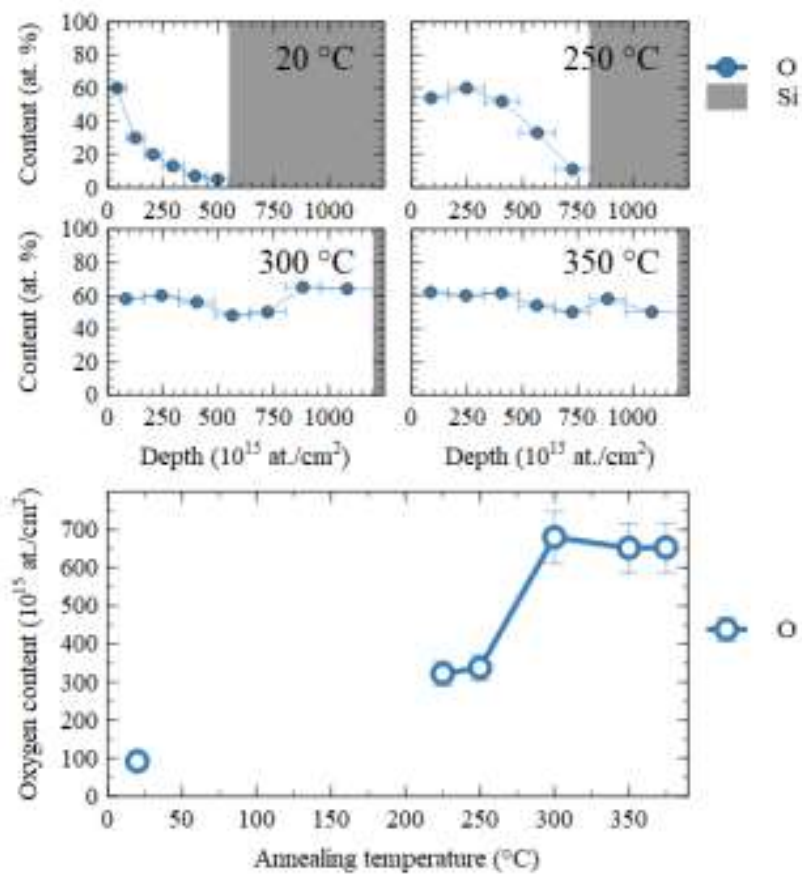

FIG. 5. Oxygen content of yttrium thin films annealed for $1 \mathrm{~h}$ under argon with traces of oxidizing impurities. 
After annealing, all the samples became insulating, even at the lowest processing temperature of $225^{\circ} \mathrm{C}$. IBA analyses revealed an oxygen content increasing from $1 \times 10^{17}$ at.cm ${ }^{-2}$ to $7 \times 10^{17}$ at. $\mathrm{cm}^{-2}$ after annealing at $300^{\circ} \mathrm{C}$. In addition, profiles show that the sample annealed at $250^{\circ} \mathrm{C}$ exhibits an $\mathrm{Y}_{2} \mathrm{O}_{3}$ oxide layer thickness of around $150 \mathrm{~nm}$, which is largely enough to make the film highly insulating. For an annealing temperature above $300{ }^{\circ} \mathrm{C}$, the $200 \mathrm{~nm}$-thick Y film is oxidized over all its thickness.

All results in this section show the high affinity of yttrium for oxygen at low temperatures $\left(\leq 300^{\circ} \mathrm{C}\right)$.

\section{B. Y-Ti alloys}

Figure 6 displays the resistivity and TCR of Y-Ti films as function of Y content, 40 days after deposition. The TCR is a good indicator of the crystalline disorder in the film ${ }^{16,25}$. The TCR of Y-Ti films are lower than the ones of single metals titanium and yttrium, and the lowest TCR are obtained with compositions close to equal content in $\mathrm{Ti}$ and $\mathrm{Y}$, as expected by the absence of definite intermetallic compounds or solid solution in the Y-Ti system ${ }^{26}$. However, the resistivity does not follow the same trend, as it is more sensitive to impurity scattering than to crystalline disorder. The Y-Ti films have a much larger resistivity than the single metal titanium film, but similar to the single metal yttrium one. The $\mathrm{Y}_{10} \mathrm{Ti}_{90}$ film has the highest resistivity. 


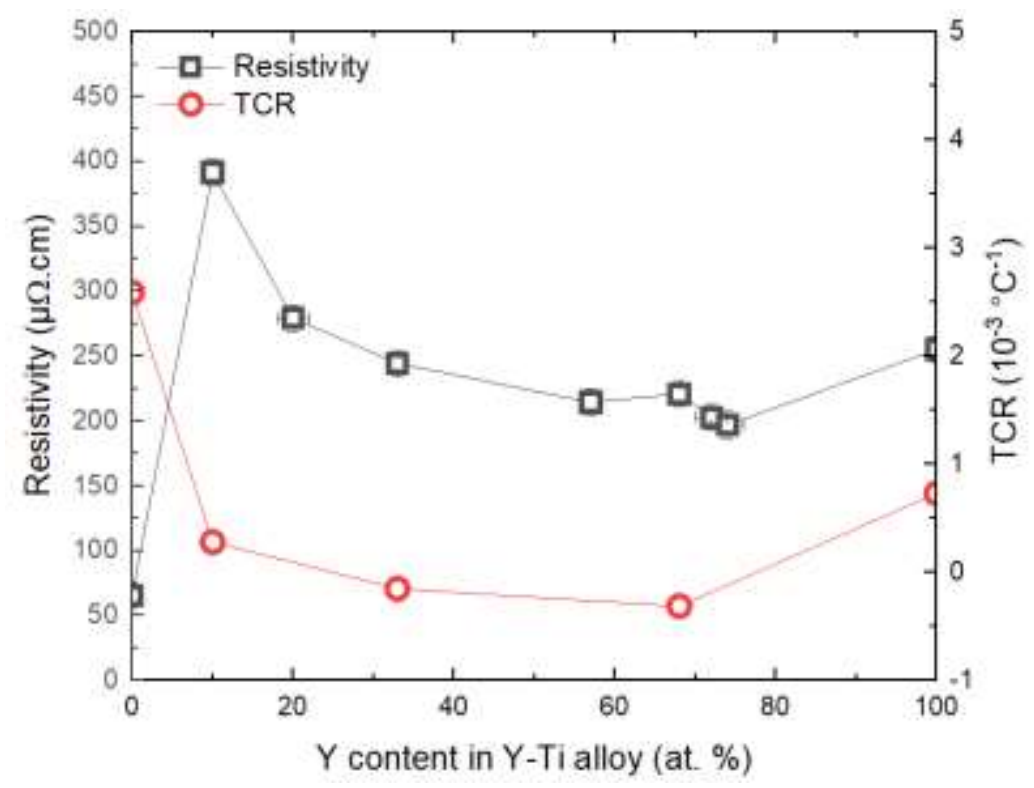

FIG. 6. Resistivity and TCR of as-deposited $200 \mathrm{~nm}$-thick Y-Ti films 40 days after deposition.

Observations of three Y-Ti film surfaces by SEM are displayed in Figure 7. The $\mathrm{Y}_{10} \mathrm{Ti}_{90}$ film exhibits a much more open structure than other $\mathrm{Y}_{\mathrm{x}} \mathrm{Ti}_{\mathrm{y}}$ films. The resulting higher effective surface is expected to lead to an increased oxygen content that would explain its very high resistivity.

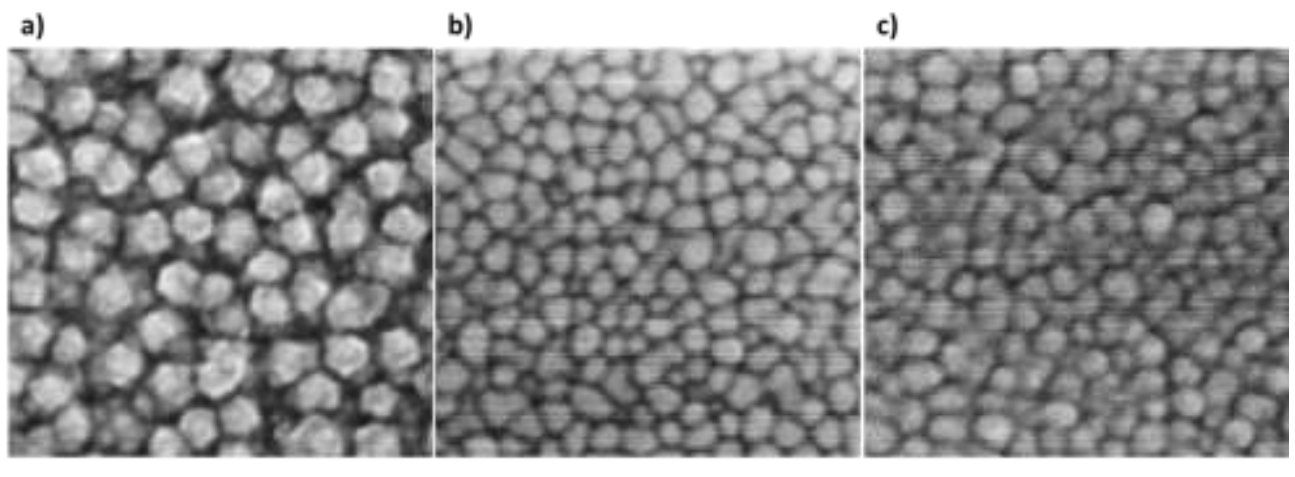

$100 \mathrm{~nm}$

FIG. 7. SEM surface images of $\mathrm{Y}_{10} \mathrm{Ti}_{90}(\mathrm{a}), \mathrm{Y}_{33} \mathrm{Ti}_{67}$ (b) and $\mathrm{Y}_{68} \mathrm{Ti}_{32}$ (c) films. 
The in-plane mean grain size (see Fig 8) is around $20 \mathrm{~nm}$ for samples containing more than $20 \%$ of yttrium. Lower yttrium content leads to larger grain sizes close to the one of single metal titanium.

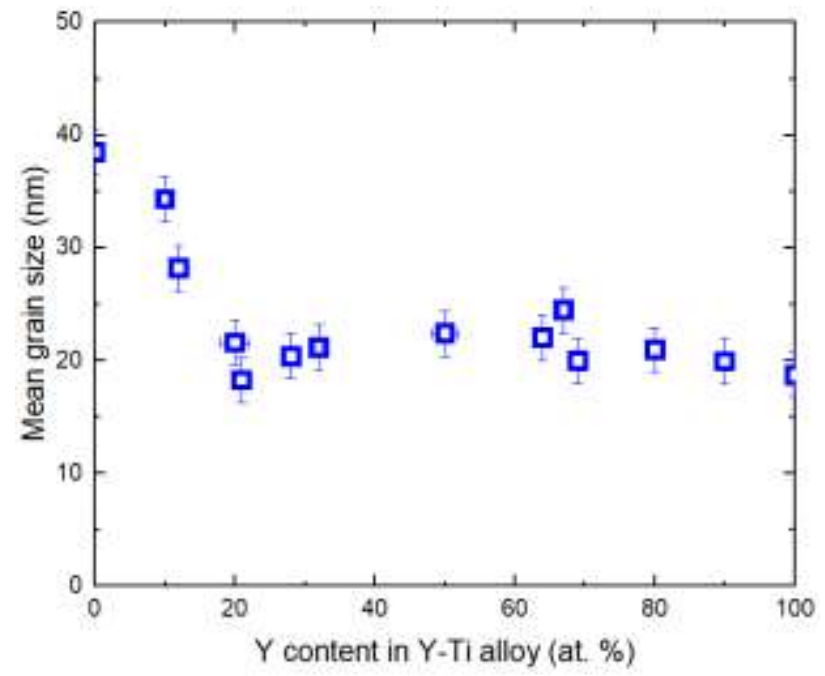

FIG. 8. In-plane mean grain size estimation measured by SEM of unannealed Y-Ti films The XRD analysis confirmed the absence of a Y-Ti solid solution, as predicted by the phase diagram ${ }^{26}$ (see Figure 9). Ti and Y crystallites were detected in Y-Ti films with high content of Ti and Y respectively. An out-of-plane grain size between 5 and $10 \mathrm{~nm}$ was deduced from the Scherrer law, which is lower than the one (35 nm) measured for the single metal yttrium film. The resulting high density of grain boundaries in the Y-Ti films contributes to their high resistivity when compared to titanium. 


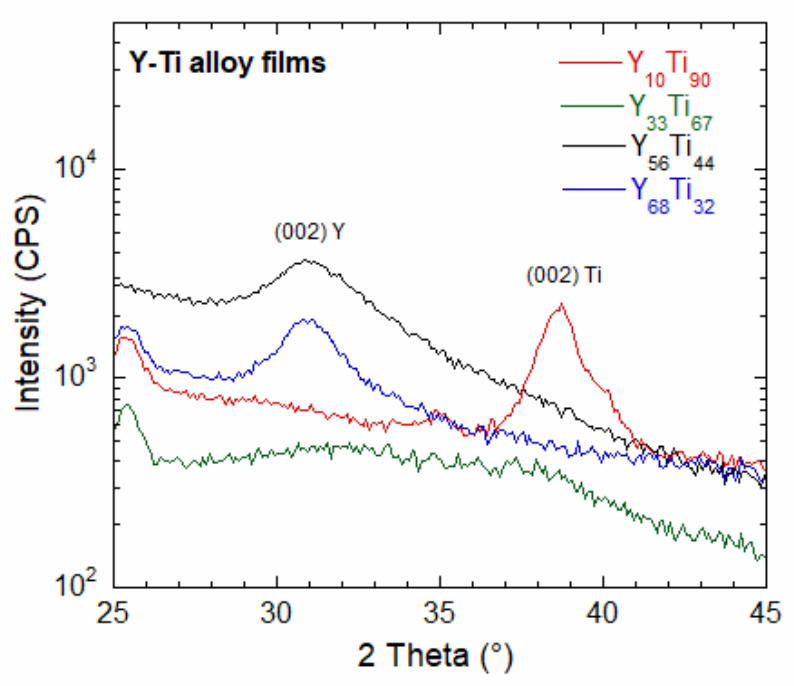

FIG. 9. XRD analysis of non-annealed Y-Ti films

The sheet resistance evolution of an $\mathrm{Y}_{56} \mathrm{Ti}_{44}$ film stored at ambient air is compared to the ones of yttrium and titanium single metal films in Figure 10. The sheet resistance of the titanium film stays nearly constant, as expected for this material known to selfpassivate in air with a stable titanium dioxide ${ }^{14}$. The sheet resistance of the $\mathrm{Y}_{56} \mathrm{Ti}_{44}$ film increases over time, but at a much lower rate than single metal yttrium.

The sheet resistances of titanium, yttrium and various Y-Ti alloyed films were measured after 280 days of exposure to air (Figure 11). The highest sheet resistance increase is obtained for the single metal yttrium film, and the lowest (almost null) increase for single metal titanium films. Concerning Y-Ti films, higher is the yttrium content, larger is the increase of its resistance. As the alloyed film is composed of both yttrium and titanium grains and because it is thermodynamically favorable (the enthalpy of formation of $\mathrm{Y}_{2} \mathrm{O}_{3}$ of $-1905 \mathrm{~kJ} / \mathrm{mol}$ is lower to the one of $\mathrm{TiO}$ of $-519 \mathrm{~kJ} / \mathrm{mol}$ and $\mathrm{TiO}_{2}$ of $-966 \mathrm{~kJ} / \mathrm{mol}^{5}$ ), it is supposed that a preferential oxidation of yttrium is at the origin of this behavior. 


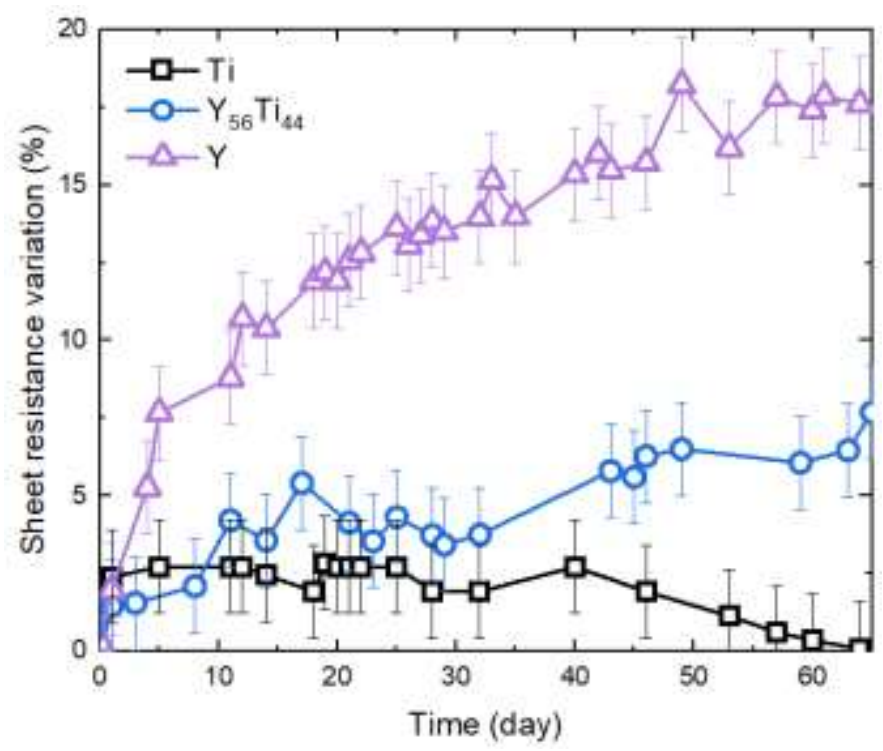

FIG. 10. Sheet resistance monitoring over time of $\mathrm{Y}, \mathrm{Ti}$ and $\mathrm{Y}_{56} \mathrm{Ti}_{44}$ films stored at ambient air (start of the measurement: $<10 \mathrm{~min}$ after exposure to air).

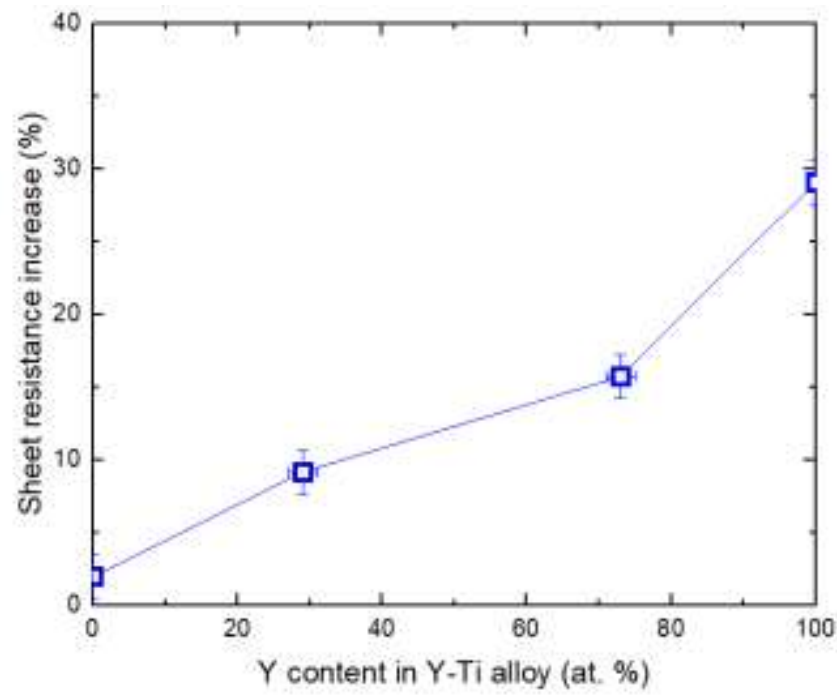

FIG. 11. Increase of sheet resistance of Y-Ti alloy films after 280 days of air exposure.

The oxygen and metals profiles of the same samples are shown in Figure 12. The alloy composition is in depth homogeneous in the bulk of the films. The oxygen profile of the $\mathrm{Y}_{10} \mathrm{Ti}_{90}$ film confirms the in-depth oxidation, which may be due to its less compact 
structure. For other samples, the surface oxygen content (25\%) in $\mathrm{Y}_{68} \mathrm{Ti}_{32}$ is higher than the one $(16 \%)$ of $\mathrm{Y}_{33} \mathrm{Ti}_{67}$, and the oxygen atoms diffused deeper in $\mathrm{Y}_{68} \mathrm{Ti}_{32}$ than in $\mathrm{Y}_{33} \mathrm{Ti}_{67}$. Thus, it confirms that oxidation, like the sheet resistance, could be is related to the Y/Ti ratio in the film: Yttrium-rich films have a higher absorption of oxygen in ambient air. However, for these films, oxygen content and diffusion depth are much lower than in single metal yttrium (cf Figure 5). Hence, compared to single metal yttrium, this demonstrates that incorporation of titanium in yttrium improves the resistance to room temperature oxidation of the alloy. 

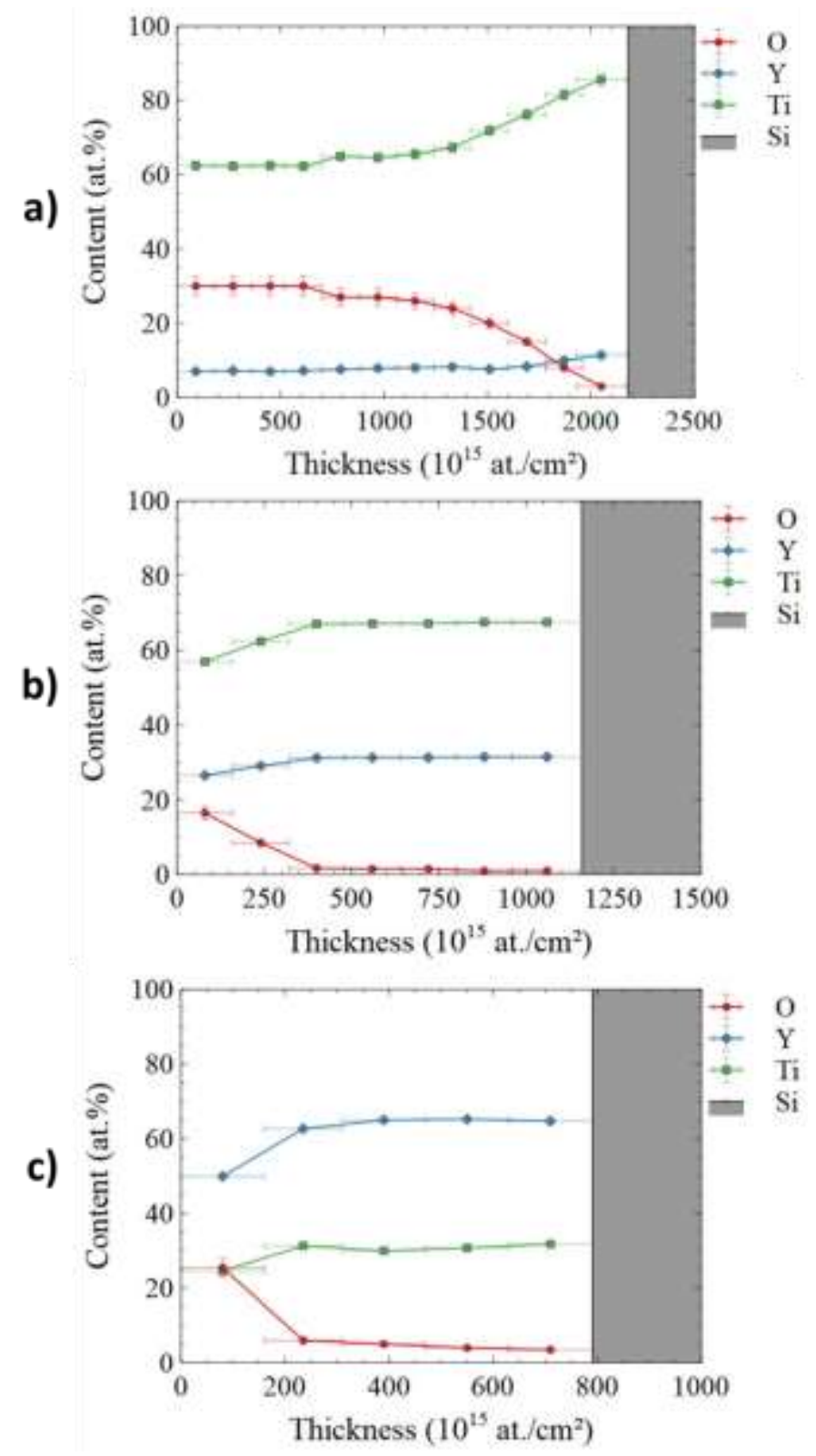

FIG. 12. Oxygen and metal profiles of $\mathrm{Y}_{10} \mathrm{Ti}_{90}(\mathrm{a}), \mathrm{Y}_{33} \mathrm{Ti}_{67}(\mathrm{~b})$, and $\mathrm{Y}_{68} \mathrm{Ti}_{32}$ (c) films after 280 days of exposure to ambient air.

The same activation process as used for yttrium, i.e. in argon with traces of oxidizing impurities, was applied to Ti and Y-Ti films.

For all films, the sheet resistance (see Figure 13) increases with the annealing temperature, at a rate that rises with the yttrium content. This trend is explained by a raise in oxygen content, as deduced by IBA analyses (see Figure 14), thus to a decrease of the 
metallic volume in the film. Single metal yttrium, $\mathrm{Y}_{68} \mathrm{Ti}_{32}$ and $\mathrm{Y}_{33} \mathrm{Ti}_{67}$ films become insulating after annealing at $225^{\circ} \mathrm{C}, 275^{\circ} \mathrm{C}$ and $350{ }^{\circ} \mathrm{C}$ respectively, while $\mathrm{Y}_{10} \mathrm{Ti}_{90}$ and Ti films remain conductive even after $400{ }^{\circ} \mathrm{C}$ annealing. So alloyed films show an intermediate behaviour between the ones of single metal yttrium (which oxidizes at low temperature) and titanium (which oxidizes at high temperature). This behaviour may originate from the dual phase structure (yttrium + titanium) in the Y-Ti alloys.

The oxygen profiles of annealed $\mathrm{Y}_{33} \mathrm{Ti}_{67}$ and $\mathrm{Y}_{68} \mathrm{Ti}_{32}$ films, (Figure 15) show that they are oxidized along their whole thickness, even after an annealing at only $225^{\circ} \mathrm{C}$. At $250{ }^{\circ} \mathrm{C}$, the decrease in the slope of the oxygen content is much lower than the one measured in single metal yttrium (Figure 5). This demonstrates a higher oxygen diffusivity in the alloyed films. This is likely related to their higher density of grain boundaries.

The consequence is that $\mathrm{Y}_{33} \mathrm{Ti}_{67}$ and $\mathrm{Y}_{68} \mathrm{Ti}_{32}$ films exhibit higher sorption property for oxygen at low temperature than single metal yttrium: if we quantify sorption by the equivalent number of sorbed $\mathrm{O}_{2}$ molecules, $\mathrm{Y}_{68} \mathrm{Ti}_{32}$ and $\mathrm{Y}_{33} \mathrm{Ti}_{67}$ films sorbed 0.5 $\mu \mathrm{mol} . \mathrm{cm}^{-2}$ of $\mathrm{O}_{2}$ after $1 \mathrm{~h}$ annealing at $250{ }^{\circ} \mathrm{C}$, while yttrium sorbed $0.2 \mu \mathrm{mol} . \mathrm{cm}^{-2}$, and n oxygen sorption for titanium was below the detection limit. Titanium already proved its getter properties for vacuum packaging at bonding temperature higher than $300{ }^{\circ} \mathrm{C}^{27}$. The comparison of the yttrium-based films with the titanium film shows their interest as getter material for packaging at low temperature.

Y-Ti thin film with yttrium content comprised between $30 \%$ and $70 \%$ appear as the most appropriate candidate for a getter presenting a low temperature activation, as it combines high oxygen sorption and a good resistance to surface thermal oxidation. Indeed, as demonstrated, a lower content in yttrium would give a lower sorption of 
oxygen at low activation temperature, while a higher content would give a lower resistance to atmospheric oxidation.

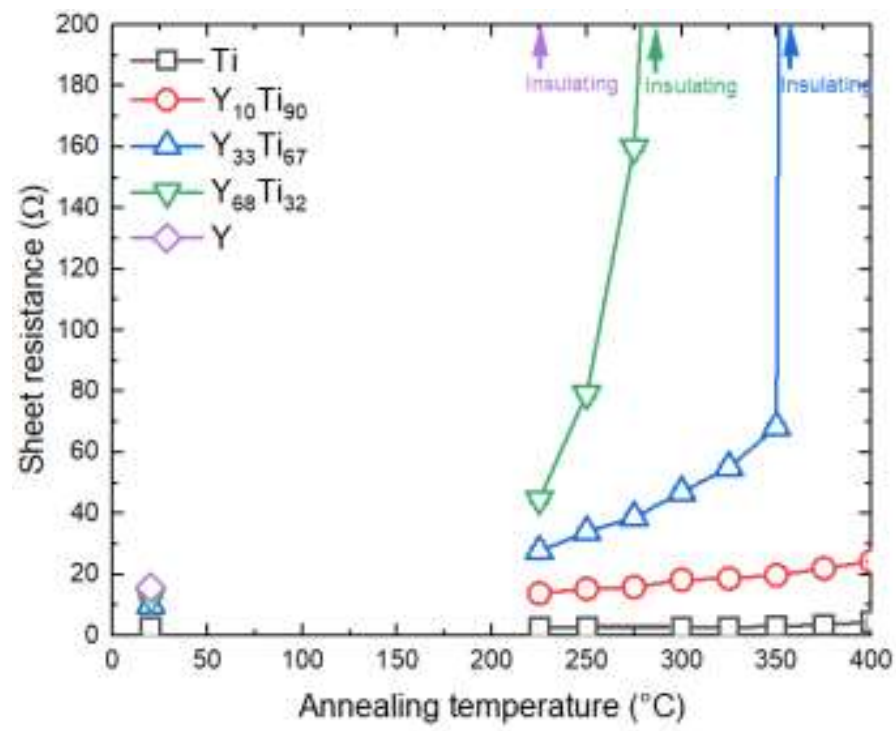

FIG. 13. Sheet resistance of $\mathrm{Y}, \mathrm{Ti}$ and $\mathrm{Y}$-Ti films after $1 \mathrm{~h}$ annealing in argon.

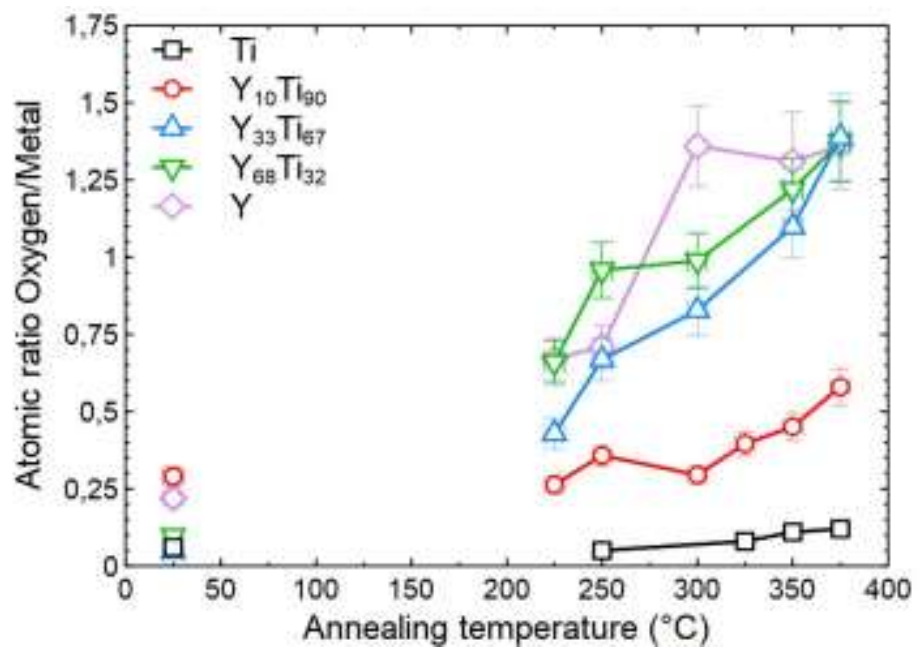

FIG. 14. Oxygen content in Y, Ti and Y-Ti films after $1 \mathrm{~h}$ annealing in argon. 


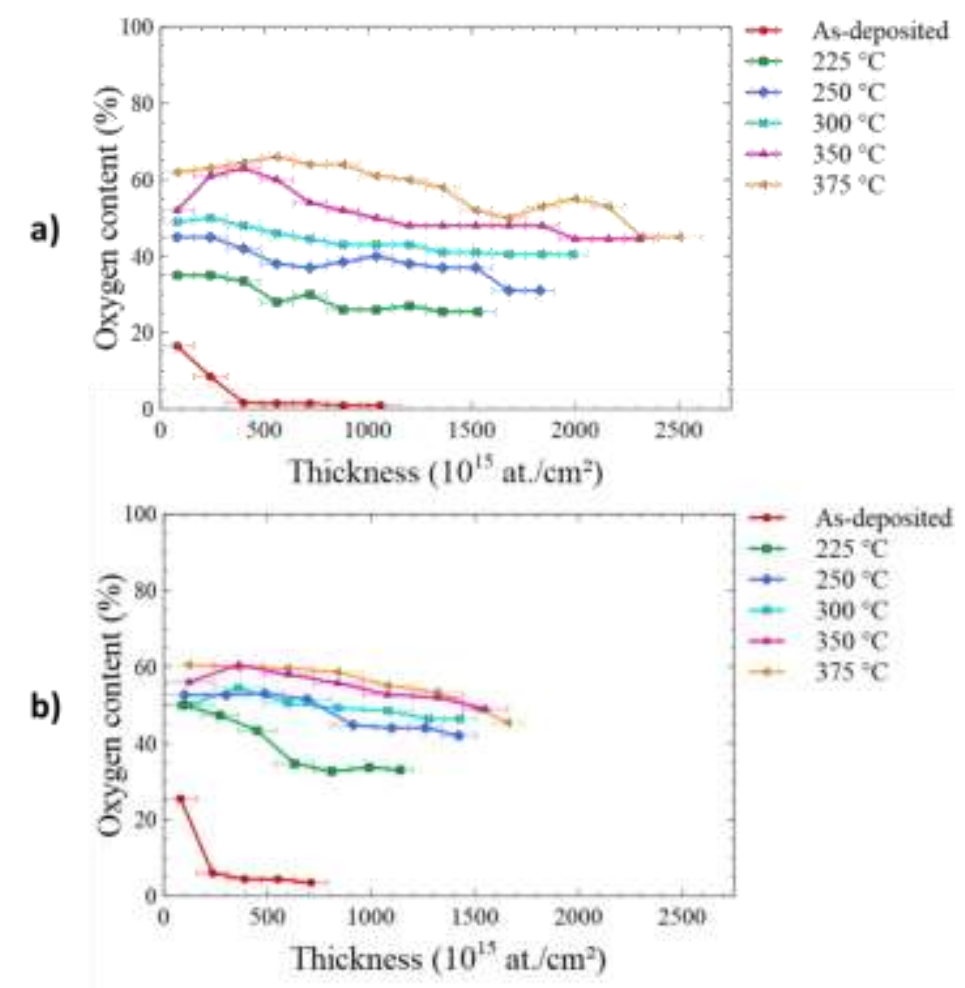

FIG. 15. Oxygen profiles in $\mathrm{Y}_{33} \mathrm{Ti}_{67}$ (a) and $\mathrm{Y}_{68} \mathrm{Ti}_{32}$ (b) films after $1 \mathrm{~h}$ annealing.

\section{Getter performances in vacuum-sealed conditions}

Three different getter films exposed 10 months to ambient air were packaged under vacuum in glass ampoules and activateded at $250{ }^{\circ} \mathrm{C}$. Table 1 reports the residual gas composition measured inside the ampoules according to their content. The IVA does not measure the exact quantity of gas trapped in a ampoule, so the pressures are given in arbitrary units.

TABLE I. $\mathrm{H}_{2} \mathrm{O}$ and $\mathrm{O}_{2}$ partial pressures measured by IVA in glass ampoule containing $102 \mathrm{~mm}^{2}$ of Y-Ti getter film after $250{ }^{\circ} \mathrm{C}-1 \mathrm{~h}$ annealing

\begin{tabular}{|r|c|c|c|c|}
\hline Ampoule content & No getter & $\mathrm{Y}_{5} \mathrm{Ti}_{95}$ & $\mathrm{Y}_{69} \mathrm{Ti}_{31}$ & $\mathrm{Y}$ \\
\hline $\mathrm{H}_{2} \mathrm{O}$ partial pressure (arbitrary unit) & $1 \times 10^{-6}$ & $1 \times 10^{-6}$ & $6 \times 10^{-9}$ & $3 \times 10^{-7}$ \\
\hline
\end{tabular}




\begin{tabular}{|l|l|l|l|l|}
$\mathrm{O}_{2}$ partial pressure (arbitrary unit) & $2 \times 10^{-10}$ & 0 & 0 & 0 \\
\hline
\end{tabular}

By comparing the $\mathrm{H}_{2} \mathrm{O}$ and $\mathrm{O}_{2}$ partial pressures of the ampoules with getters with the ones of the ampoule without getter, the sorption performance of the getters in vacuumsealed conditions is emphasized. The Y 5 Ti95 film did not sorb water vapour but only the traces of $\mathrm{O}_{2}$, demonstrating an almost negligible activation at $250{ }^{\circ} \mathrm{C}$, as expected from our previous measurements for Y-Ti films with low yttrium content $(<30 \%)$. The pure yttrium film sorbed all the $\mathrm{O}_{2}$ and $60 \%$ of the $\mathrm{H}_{2} \mathrm{O}$ outgassed by the glass walls, while the $\mathrm{Y}_{69} \mathrm{Ti}_{31}$ film sorbed all the $\mathrm{O}_{2}$ and more than $99 \%$ of the $\mathrm{H}_{2} \mathrm{O}$. This demonstrates that these two getters were activated at $250{ }^{\circ} \mathrm{C}$, and confirm the higher sorption performance of Y-Ti film over Y.

\section{IV.SUMMARY AND CONCLUSIONS}

Yttrium, titanium and Y-Ti thin films were elaborated by co-evaporation under UHV. Y-Ti films exhibit nanometric crystallites size $(5-10 \mathrm{~nm})$, smaller than the one of single metal yttrium $(35 \mathrm{~nm})$. This leads to a very high grain boundary density in the films, which is a favorable microstructure for low temperature oxygen diffusion, and thus gettering properties. The yttrium film is not passivated after exposure to ambient air and instead continuously oxidizes over a period as long as one year. A stronger resistance to air oxidation at room temperature was proved for Y-Ti film, depending of the yttrium content in the alloy. Y-Ti film with an yttrium content higher than $30 \%$ showed large sorption in oxygen after annealing at temperature as low as $250^{\circ} \mathrm{C}$ : it was estimated that the equivalent of $0.5 \mu$ mol.cm ${ }^{-2}$ of $\mathrm{O}_{2}$ were absorbed by a $200 \mathrm{~nm}$-thick $\mathrm{Y}_{68} \mathrm{Ti}_{32}$ film, while Y absorbed $0.2 \mu$ mol. $\mathrm{cm}^{-2}$, and no oxygen sorption was detected for Ti. This makes 
$\mathrm{Y}_{\mathrm{x}} \mathrm{Ti}_{100-\mathrm{x}}$ with $30<\mathrm{x}<70$ suitable candidates for packaging MEMS under vacuum with low bonding temperature.

\section{ACKNOWLEDGEMENTS}

This work was partially funded by the "Agence Nationale de la Recherche" (project ANR-19-CE08-0011) and by the French RENATECH network. The authors wish to thank Abdelhanin Aassime, Laetitia Leroy, Fabien Bayle, Cédric Villebasse for their work allowing a good operation of deposition, annealing and characterization set-ups in $\mathrm{C} 2 \mathrm{~N}$ clean room facilities.

\section{DATA AVAILIBILITY}

The data that support the findings of this study are available from the corresponding author upon reasonable request.

\section{REFERENCES}

${ }^{1}$ A. Hilton, D. S. Temple, "Wafer-Level Vacuum Packaging of Smart Sensors", Sensors, Volume 16, 1819 (2016)

${ }^{2}$ C. Benvenuti, P. Chiggiato, F. Cicoira, and Y. L'Aminot, "Nonevaporable getter films for ultrahigh vacuum applications", Journal of Vacuum Science \& Technology A, Volume 16, No 148 (1998)

${ }^{3}$ T. Miyazawa et al, "Oxygen-free palladium/titanium coating, a novel nonevaporable getter coating with an activation temperature of $133^{\circ} \mathrm{C}^{\prime}$, Journal of Vacuum Science \& Technology A, Volume 36, 051601 (2018) 
${ }^{4}$ O.B. Malyshev, R. Valizadeh, A.N. Hannah, "Pumping properties of Ti-Zr-Hf-V nonevaporable getter coating”, Vacuum, Volume 100, pp. 26-28 (2014)

${ }^{5}$ A. Bosseboeuf et al, "Effect of Environment on Activation and Sorption of Getter Alloys and Multilayers for Hybrid Wafer-level Vacuum Packaging”, Sensors and Materials, Volume 31, No 9, pp. 2825-2849 (2019)

${ }^{6}$ W. C. Welch, "Vacuum and Hermetic Packaging of MEMS using Solder", PhD thesis (2008)

${ }^{7}$ A. Hilton et al, "Wafer-Level Vacuum Packaging of Microbolometer-base Infrared Imagers", proceedings of the International Wafer-Level Packaging Conference IWLPC (2016)

${ }^{8}$ X. Wang et al, "Wafer-Level Vacuum Packaging Enabled by Plastic Deformation and Low-Temperature Welding of Copper”, Journal of Microelectromechanical Systems, Volume 26, No 2 (2017)

${ }^{9}$ M. S. Al Farisi, H. Hirano, S. Tanaka, "Low-temperature hermetic thermo-compression bonding using electroplated copper sealing", Sensors and Actuators A: Physical, Volume 279, pp. 671-679 (2018)

${ }^{10} \mathrm{X}$. Wang et al, "Wafer-Level Vacuum Sealing by Transfer Bonding of Silicon Caps for Small Footprint and Ultra-Thin MEMS Packages", Journal of Microelectromechanical Systems, Volume 28, No 3 (2019)

${ }^{11}$ D. Chagnon, "Encapsulation hermétique de microbolomètres pour caméras infrarouges", $\mathrm{PhD}$ thesis (2018)

${ }^{12}$ J. N. Huiberts et al, "Synthesis of yttriumtrihydride films for ex-situ measurements", Journal of Alloys and Compounds, Volume 239, No 2, pp. 158-171 (1996)

${ }^{13}$ M. Fattahzadeh, A. Kaflou, V. Dashtizad, "Effect of milling and adding yttrium on sorption characteristics of $\mathrm{Zr}$-Co based nanostructure chemical getter", Journal of 
Alloys and Compounds, Volume 846, 155329 (2020)

${ }^{14} \mathrm{~L}$. Tenchine et al, "NEG thin films for under controlled atmosphere MEMS packaging", Sensors and Actuators A: Physical, Volume 172, pp. 233-239 (2011)

${ }^{15} \mathrm{~S}$. Li, Y. Shu, J. Fan, “Thickness and component distributions of yttrium-titanium alloy films in electronbeam physical vapor deposition", Science in China Series E: Technological Sciences, Volume 51, pp. 1470-1482 (2008)

${ }^{16} \mathrm{~S}$. Lemettre et al, “ In-situ electrical characterization of co-evaporated $\mathrm{Zr}$ - $\mathrm{Ti}, \mathrm{Zr}-\mathrm{V}$ and $\mathrm{Zr}$ Co thin getter films during thermal activation", Microsystem Technologies, Volume 25, pp. 4091-4096 (2019)

${ }^{17}$ M. Mayer, "SIMNRA, a Simulation Program for the Analysis of NRA, RBS and ERDA", Proceedings of the 15th International Conference on the Application of Accelerators in Research and Industry, American Institute of Physics Conference Proceedings, Volume 475, No 541 (1999)

${ }^{18}$ A. F. Gurbich, "SigmaCalc recent development and present status of the evaluated crosssections for IBA”, Nucl. Instr. and Meth. B, Volume 371, pp. 27-32 (2016)

${ }^{19}$ A.E Curzon and O. Singh, "Thin film studies of yttrium, yttrium hydrides and yttrium oxide", J. Phys. F, Volume 8, No 8 (1978)

${ }^{20}$ A. K. Burnham, G. T. Jameson, "Oxidation kinetics for thin rare-earth metal films”, Journal of Vacuum Science \& Technology A, Volume 5, No 4 (1987)

${ }^{21}$ R. Reichl, K. H. Gaukler, “An investigation of air-grown yttrium oxide and experimental determination of the sputtering yield and the inelastic mean free path”, Applied Surface Science, Volume 26, No 2, pp. 196-210 (1986)

${ }^{22} \mathrm{D}$. Moldarev et al, "Composition of photochromic oxygen-containing yttrium hydride films", Solar Energy Materials and Solar Cells, Volume 177, pp. 66-69 (2018)

${ }^{23}$ M. K. Loudjani, C. Sella, "Models of Electric Transport in Bilayer Ni/Cu And in a Tri- 
layer Ni/Pd/Cu Thin Films”, International Journal of Thin Films Science and Technology, Volume 6, No 3, pp. 113-116 (2017)

${ }^{24} \mathrm{~F}$. Bezuidenhout and R. Pretorius, "The optical properties of evaporated Y2O3 films", Thin Solid Films, Volume 139, pp. 121-132 (1986)

${ }^{25}$ V. F. Gantmakher, “Mooij Rule and Weak Localization”, JETP Letters, Volume 94, pp. 626-628 (2011)

${ }^{26}$ J. L. Murray, “The Ti-Y System, Phase Diagrams of Binary Titanium Alloys”, J.L. Murray, Ed., American Society for Metals, Metals Park, OH, pp. 333-335 (1987)

${ }^{27}$ V. Chidambaram, X. Ling and C. Bangtao, "Titanium-Based Getter Solution for WaferLevel MEMS Vacuum Packaging”, Journal of Electronic Materials, Volume 42, No. $3(2013)$ 